\title{
Positive community responses to an arts-health program designed to tackle diabetes and kidney disease in remote Aboriginal communities in Australia: a qualitative study
}

\author{
Craig Sinclair, ${ }^{1}$ Annette Stokes, ${ }^{1}$ Christine Jeffries-Stokes, ${ }^{1}$ Jeanne Daly ${ }^{2}$
}

Aus he state of Aboriginal health in Australia is widely seen as a national disgrace. Aboriginal life expectancy is about a decade less than for other Australians. ${ }^{1}$ This discrepancy is attributed to multiple intergenerational causes. Racism experienced by Aboriginal people has been described as "enough to make you sick,", and is exacerbated by poor education, inadequate and overcrowded housing, and lack of access to health services. These discrepancies are much worse for Aboriginal people living in remote areas of Australia. Here, the difference in life expectancy rises to 17 years. ${ }^{1}$

If Aboriginal health in remote areas is a major cause for concern, one might expect a concentration of clinical and preventive services in these areas. The opposite is true. In 2014, the Australian Federal Government cut more than $\$ 500$ million from Aboriginal programs, ${ }^{3}$ including health programs, with the expectation that state governments would pick up the shortfall. In more recent times, both the Federal and Western Australian State Governments have indicated their intentions to withdraw services leading to the closure of more than 100 of the state's remote communities - citing social disadvantage, poor health and the need to centralise services for economic reasons. ${ }^{4}$

The history of treating kidney disease in remote areas shows why this is the wrong way to go. End-stage renal disease is seven times higher among Aboriginal people, ${ }^{5}$ but

\begin{abstract}
Objective: The Western Desert Kidney Health Project (WDKHP) is an innovative clinical screening, arts-health and community development program, staffed by Aboriginal health workers. The WDKHP is aimed at prevention and early detection, improving the chance of better management of kidney disease among people in 10 predominantly Aboriginal communities in rural Western Australia. This paper aimed to understand community responses to the WDKHP in three of these communities.

Methods: Interviews were undertaken with 26 Aboriginal people living in three remote communities. Community responses were analysed with attention to the social organisation of participants in each community and a focus on the perspectives of key groups, identified here as 'Community Leaders,' 'Homelanders,',Refuge Seekers' and 'Dislocated'.

Results: Participants from all groups reported that the WDKHP was highly acceptable, and an effective means of drawing attention to the need for prevention, early detection and management of diabetes and kidney disease. The integration of Aboriginal health workers to explain the project contributed to the high rates of participation in clinical screening.

Conclusions: Outreach clinical services can be an appropriate method of engaging people in remote communities in addressing diabetes and kidney disease.

Implications: The remote community setting can act as an 'enabler' of healthy lifestyle for Aboriginal people, particularly when augmented by well-designed outreach programs.

Key words: Aboriginal, kidney, diabetes, arts-health, remote, participatory
\end{abstract}

in remote areas it has been assessed as 30 times the national average. ${ }^{6}$ When patients relocate to towns for access to dialysis and other specialist services, they experience heavy social, emotional and financial cost from family and cultural disruption. ${ }^{7}$ Many choose to forego treatment to die at home. ${ }^{8}$ In the process, the cost to government is transferred to patients, families and communities.

\begin{abstract}
The most cost-effective solution to treating kidney disease in remote communities is well known: comprehensive clinical services focused on early detection and treatment of diabetes, ${ }^{9}$ supplemented by prevention programs to facilitate lifestyle changes. ${ }^{10}$ There are substantial challenges when implementing any of these strategies in isolated remote communities. Cultural differences, along with a deep fear of kidney disease and its consequences, may
\end{abstract}

\footnotetext{
1. Rural Clinical School of Western Australia, University of Western Australia 2. Independent researcher, Victoria

Correspondence to: Dr Craig Sinclair, Rural Clinical School of WA, M701, University of Western Australia, Hackett Drive, Crawley, WA 6009; e-mail: craig.sinclair@rcswa.edu.au Submitted: March 2015; Revision requested: June 2015; Accepted: December 2015

The authors have stated the following conflict of interest: Two of the authors (AS, CJ-S) were involved in the design and implementation of the program that is the subject of this paper. These authors did not participate actively in the data collection, but contributed to the design of the evaluation project, data analysis and write up. This evaluation project was funded by a small project grant from the Rural Clinical School of WA.
} 
contribute to new interventions being viewed with suspicion. Effective programs that engage communities can take many years of planning, and need close attention to developing trust and rapport. ${ }^{11}$

The Western Desert Kidney Health Project (WDKHP) took on this challenge, aiming to reduce the prevalence and burden of diabetes and kidney disease in 10 predominantly Aboriginal communities in the Goldfields region of Western Australia ${ }^{12}$ through early diagnosis together with a better understanding of prevention of these diseases. A truck was equipped to deliver a clinical screening program. It visited each community annually for three years, staying for about two weeks each time. The aim was to screen all community members for diabetes and kidney disease. The clinical team was led by Aboriginal health workers, including one worker with close family ties and cultural authority within the communities. They met with the community, invited people to participate in clinical screening and provided culturally appropriate explanations of the project aims.

A screening service, while important, is insufficient for these communities. The diagnosis of a feared disease, without accompanying support, could be a source of trauma for people ${ }^{13}$ who fear kidney disease and know of the burden associated with relocation for treatment. ${ }^{14}$ An innovative component of this project was the use of a second truck that delivered community arts programs focused on positive, culturally appropriate health messages. Artists engaged community members to convey the message that kidney disease can be confronted and prevented. In one arts intervention, community members were then encouraged to use traditional sand-drawing techniques to produce community-led stories with locally relevant health messages about kidney health ${ }^{15}$. Each arts residency typically coincided with the clinical truck visit, lasting for two weeks and ending with participants exhibiting or performing their creative work to the entire community. Following each visit, a community development officer (based with the WDKHP team in the regional city) worked with the community, facilitating solutions to structural issues. This work ranged from community advocacy (e.g. towards provision of healthy foods in shops or roadhouses), to assistance in preparing grant applications for community infrastructure. ${ }^{16}$
Conducting a program like this is challenging, but it is even more difficult to assess whether the effects are positive. The project's clinical outcomes can only be assessed over a longer period of time and the data are under preliminary analysis. Our focus in this paper is on an essential early part of the project: to assess community responses to the WDKHP, and the suitability of this outreach program within the remote community context in which it was delivered.

\section{Methods}

Conventional research methods have been criticised for privileging Western world views, and marginalising Indigenous world views. ${ }^{17}$ Sherwood argues that research itself must be 'decolonised'; in particular, by understanding the contexts within which knowledge and practice originate. ${ }^{18}$ Our aim was to conduct a qualitative interview study but to ensure that our methods were responsive to these contexts, in particular the specific circumstances and commitments experienced by those living in the remote community setting. The study methods were approved by the University of Western Australia Human Research Ethics Committee and the Western Australian Aboriginal Health Ethics Committee.

\section{Study design}

We knew from the results of the first visit to these communities that the majority of the population had markers for kidney disease. That means that most people in the community were affected by the diagnosis either personally or through a family member. Despite this, participation in clinical screening among Aboriginal people across the 10 communities was documented to be more than $80 \%$, with higher uptake among a number of the remote communities. ${ }^{16}$ This suggested that the combined program was addressing the fear engendered by the disease. The question, then, was to identify how this came about.

Field trips began in September 2012, at the same time as the second annual visit of the trucks to three desert communities. Aboriginal co-researchers with connections to each community were employed, joining the research team to advise on culturally appropriate behaviour, oversee the data collection and vouch for the main interviewer (CS) in each community. Additional activities, such as playing music and basketball, and accompanying community members on excursions to the surrounding bushland, helped to build rapport. The main interviewer and co-researcher went from house to house, explaining the study and inviting people to take part in video-taped or audio-taped interviews.

We needed broad eligibility criteria to assess community responses among this shifting, difficult-to-define population. Research team members with cultural authority and knowledge of the local community guided initial recruitment to ensure that participants were broadly representative of people present and active in each community. In addition to ensuring that different age groups and genders were represented, we also ensured that there were sufficient people with direct experience with kidney disease, either personally or in a close family member. As data accumulated, it became clear that there was remarkable agreement in approval of the program. Different reasons for this approval emerged from the interviews as data analysis proceeded. Following standard qualitative research procedures, ${ }^{19}$ the sample was diversified, eventually going beyond people resident in the communities at the time to include those who had had to move to regional centres such as Kalgoorlie.

All participants in the study provided written consent. Twenty-six adult community members with a broad age range (11 male, 15 female), evenly representing the three communities, were interviewed, and only one person declined an invitation to participate. Participants were interviewed in locations where they felt comfortable. Owing to time constraints, family responsibilities or mobility issues, some people were interviewed at home, but mobile recording equipment and a four-wheel drive vehicle enabled some participants to be interviewed outdoors, in places of special significance to them.

Due to the large distances involved and time and budgetary constraints, data collection took place during concentrated periods of field work, lasting two to three weeks in each community. Interviews were conducted in English and employed a 'yarning' approach. ${ }^{20}$ We report verbatim the language used by the people interviewed, because it shows how they expressed ideas that could be challenging for them. Some specific terms were spoken in Wongutha language; these were translated by the Aboriginal coresearcher. Prompts such as 'how is it for your health living in [community]?' and 'what 
sorts of things do you do to keep healthy?' were used to generate discussion about health. During the latter part of the interview, participants were asked about the impact of the WDKHP on themselves and their community.

The transcript from each interview was reviewed by the researchers and discussed at team meetings. The main interviewer kept reflective journal entries relating to each interview, as well as a daily log of observations during the seven-week period of field work. One of the researchers (AS), a senior Wongutha woman, confirmed translations and provided input regarding the cultural context of participants' responses.

\section{Results}

The three Aboriginal communities where the interview study was to be conducted represented unique settings and the first research act was to understand the communities from the perspective of the people living there.

It is only two generations since the Western Desert people roamed large tracts of land without building permanent dwellings or cultivating crops; they lived on what they gleaned from the desert. The discovery of rich gold deposits in the late $19^{\text {th }}$ century and an influx of miners of predominantly European origin led to dispossession of traditional land by mining and later pastoral leases. Some Aboriginal people gravitated to camps on the fringes of these settlements or sought refuge in church missions set up to house them..$^{21,22}$

The missions have now closed but desert communities survive, including the three small communities (referred to with pseudonyms) where our interview study was based. They are situated $200-500 \mathrm{~km}$ from the nearest regional centre (Kalgoorlie) and have fluctuating populations of about 50 people. 'Salt Lake' started as a mission in the early 1900 s but then returned to Aboriginal community control. 'Claypan' was the site of a ration depot in the 1980s until negotiation between local Elders and government officials endorsed its role in maintaining a traditional Aboriginal homeland. 'Spinifex' was established to repatriate Aboriginal peoples displaced by nuclear weapon testing in the $1950 \mathrm{~s}^{23}$ who were for a time resettled at a mission before being displaced again due to water shortages.
These communities provide basic services such as a primary school (with computing facilities), a co-ordinator's office, maintenance equipment, a diesel generator and a dam or water pump. There are no shops or public waste disposal services. Health clinics previously existed in all three communities, but have been withdrawn. While the communities sometimes appear deserted, there is a steady flow of people who live between multiple communities, as well as visitors from other communities and towns. Residents often travel or relocate for extended periods (due to family obligations, ceremonial duties or accessing health services). The cultural authority of traditional Elders is integral to the maintenance of social norms. An important example is the banning of alcohol consumption, through the establishment of by-laws that mark these as 'dry' communities.

\section{Interpreting the Interviews}

Early in the process of data analysis, it became evident that there was almost complete agreement from everyone interviewed that the WDKHP was very good, addressed community needs and should be extended. There was unanimous support for the value of an outreach clinical screening service. The children's sand animation videos were greeted with pride and joy. This posed a problem: it was unclear whether this unanimity reflected genuine support for the WDKHP, or was instead a product of the enmeshed relationships in the small communities involved. We turned our attention to the study setting, trying to understand the social organisation of the communities and the conditions in which people were living, to find contextual explanations for the strong uniform views expressed. Based on close reading and categorisation of participant narratives as well as the contextual information, we identified four categories of respondents: 'Community Leaders,',Homelanders,', RefugeSeekers' and the 'Dislocated'. These categories cannot adequately capture the complexity of participants' lives or social roles in their communities, but they show how differences in circumstance contributed to the different reasons given in support of the WDKHP.

\section{Community Leaders}

Six of the respondents were identified as Community Leaders; these people included Elders, with ceremonial responsibilities and cultural authority based on family lineage, as well as community co-ordinators (who were typically middle-aged), who undertook practical leadership roles on a daily basis. What they all had in common was strong links to Country. One of the men interviewed explained that people in this desert region were all living "under one big umbrella", the overarching connection to the Country of the desert people. Within this umbrella people have their own specific Country, defined by either maternal or paternal ancestry. ${ }^{24}$ These connections to Country are ever present for the Community Leaders but they also appear to be retained even when people move away to other communities or regional towns.

The Community Leaders felt qualified to speak on behalf of their communities, emphasising the importance of education and traditional culture for maintaining health. One Elder, a 'law-man', recalled how, in his youth, people lived a traditional lifestyle and did not know of kidney disease. The transition to towns and loss of culture had led to drinking alcohol and other unhealthy behaviours, passed on through family networks:

In long time ago been bush, been our great grandfather theybeeneating meat, kangaroo meat, emu... you know bush meat, grow up on that... But today people you know, they forgot about their culture, theylearn the new things in towns and cities, where there's pubs you know? Open, just to drink to enjoy their life you know, our people today. And they get sick, end up in hospital. Our little young generation today, they catch it from their parents, you know?

In Claypan, a community coordinator spoke of the difficulties people experienced when the community health clinic closed; hence the importance of mobile outreach services:

[Regional health service], they'vegot a mobile clinic, and we really need them to come out but they haven't been out here and Western Desertmob [WDKHP] they have been outhere a second time, which we are grateful for. It's helping us and all our children... it's really preventing us from going that way of kidney failure and diabetes.

In Salt Lake, the son and daughter-in-law of the community's respected Elder illustrated their symbolic acceptance of the WDKHP. Despite having been screened in Salt Lake during a previous visit from the WDKHP, they made a conscious decision to publically support the WDKHP by also visiting a nearby town to get screened when the WDKHP arrived there. They felt that this public 
support for the project would encourage others to participate:

Well I know a lot of Wongis said "My kidney's good", like all would say that you know...

"Oh we're right and we don't need to go" and whatever. But we had [WDKHP truck] out here, but we still went into [rural town] and supported them, and encouraged people to all come along too. [People said] "Oh mission mob all here". Ana we all went into town. That's when [the WDKHP] first started off.

While Community Leaders are committed to the survival and protection of their communities, the communities themselves can be fragile. A year after the first visit from the WDKHP, Spinifex had effectively ceased to exist. The meagre range of government services was withdrawn and, despite the efforts of Elders, community relations soured and people had moved away.

\section{The Homelanders}

The eight respondents identified as Homelanders did not have formal leadership roles, but spoke of strong ongoing connections to community, an affinity to bush life and a sense of belonging - of being at home. They had all spent some time away, due to family or work obligations, but always returned to their own community. They valued the active lifestyle, availability of healthy bush foods, and lack of access to alcohol or takeaway foods. Many of them had young children, for whom the remote community provided a safe environment. Being aware of the prevalence of diabetes and kidney disease in the community, they accepted the need for screening and were concerned about the lack of health services and facilities in the community. Hence, the arrival of the WDKHP truck was very welcome. One of these participants referred to the problem of people having to travel to regional towns for health care: "Mainly all the single, little young family, haven't got cars".

The service provided by the WDKHP was generally seen as better than they could access in town. One woman particularly appreciated the Aboriginal health workers employed by the WDKHP:

Well we knew the people who came, because I've known them for a long time... They talked to us, told us what's going to happen. Yeah, encouraged us and explained it so we could understand what it was about. And that's good, they explain it to us, so we know. Because when you go into town, they don't explain too much properly. They use all the big words. Whereas, we know them, and they explain it so that we can understand.

Others expressed appreciation about having access to health workers of the appropriate gender to discuss sensitive health issues. One community member talked about her fear that the screening might show up kidney disease and her relief when the test showed that everything was clear. Along with others in the community, she was also initially wary of the screening, thinking it might reveal recent instances of alcohol consumption after a trip into town. Explanations by the health workers were able to allay her concerns and encourage participation.

\section{Refuge Seekers}

Five of the study participants described difficult social situations, and viewed the remote community as a place where they could escape unhealthy influences and adopt a healthier lifestyle. One man came to Claypan while on parole from prison, and appreciated the improvement in his diet and the lack of access to alcohol. One young woman spoke of escaping from a negative family situation in a regional town by coming to Claypan with her daughter to stay with family members. An older woman decided to relocate to Salt Lake, seeking a change in her lifestyle after being diagnosed with diabetes. All these participants talked of previous difficulties with alcohol, and cited the lack of access to alcohol in the remote community as a key benefit. The idea of escape was prominent for this group, as exemplified by this man who moved to Claypan after a family member died from kidney disease:

My wife, she's real happy that we moved out here, because I don't do much drinking anymore... when I was in [town] used to bea everyday thing for me. Used to wake up, you know go and look for a drink or anything, but now don't do that anymore.

These views fit with the aims of Claypan's Elder who had participated in the 1980s transition of Claypan from a ration depot to a community focused on maintaining traditional Aboriginal values. His commitment is that the community should provide support for lifestyle changes:

And I try and help and tell them "You come up here, well, we try to help you to keep off the drink and all that stuff, you know, drugs and stuff." That's why we build this place up ... So that's how [Claypan] start getting going then.
These respondents valued the role of their community as a place of refuge, and hence welcomed the WDKHP's outreach service, which meant that they could access health services without having to return to town, where alcohol is freely available:

When I was in [town] I was drinking, you know? I get off the drink for my health, don't want to go backward. But when I see other people drinking then, you know, when you been there it's a bit easy, a bit easy to say yes to it...

Many of the people in these communities had been warned about kidney disease but ignored the warnings. When the WDKHP screening process detected kidney disease, as it did in the majority of the people screened, it was a shock but - as one woman recorded - the WDKHP health workers were there to support her to make a change in her lifestyle:

[My health] was pretty terrible, but when I met [WDKHP health workers] you know it really opened my eyes up about my health and that... stop drinking and smoking.

Further follow-up reinforced the need to stop smoking, stay sober and eat fresh fruit and vegetables to prevent further harm to her kidneys. She started eating "bush tucker" and kangaroo meat. The gains that flow from the WDKHP are real, but there are also practical difficulties associated with adopting healthier lifestyles. She talked about having to save money for the long drive into town, where fruit and vegetables "cost an arm and a leg".

Another man who had relocated to Claypan spoke of the value of the education and health promotion provided by the community arts aspect of the WDKHP:

We look forward for the kidney mob come out ... well my kids... they really lookforward to it, all the movies and sand animation and all that there, and they even come home and lecture me what to eat, what's right and wrong.

Here, we see an example of the role of the WDKHP's arts-health approach, generating new confidence in the children in knowing about healthy lifestyle and exercising a positive influence within their family.

\section{The Dislocated}

The most difficult interviews were with community members who had been forced to relocate to town. Seven respondents were identified as 'Dislocated' from their communities, and were interviewed in Kalgoorlie, or outlying towns. Like the Homelanders, they appreciated the health 
benefits of life in the remote community and lamented their experience of being forced into town.

In the case of the Spinifex community, the withdrawal of health services and closure of the shop and school led to immense pressures on community members. Following the withdrawal of the community nurse, one man with an ongoing heart condition felt he had to move to Kalgoorlie to be closer to medical help. One woman had previously worked at the Spinifex community school, teaching the children in Wongutha language. She struggled with the transition to life in Kalgoorlie, where classes are taught in English and her children feel'shame' when going to school. She experienced constant worry about the authorities taking her children into custody, despite her long history of responsible parenting and community service.

Ongoing health problems were a common reason for relocation. One senior man was forced to relocate to Kalgoorlie, even though "it broke my heart" that he had to go on dialysis for his kidney disease. Now, he says: "... my life is horrible, like I'm stuck up on the kidney machine...." Those with important community responsibilities felt the loss of personal identity, as well as the loss of connection to Country. Some senior people talked about how they would return to Country to undertake important obligations, even when this meant missing a dialysis appointment. But those forced to relocate to town did not come alone. Entire families were uprooted. Family members who accompanied them had to find a place to live, either with extended family or friends, shortterm hostels, or squatting in fringe camps.

The two participants who had been forced to move away from their communities to seek treatment for kidney disease strongly endorsed the preventive role of the WDKHP as a way of "helping people to look at what is the causing the problems" and thereby preventing future generations from experiencing the same fate. One man spoke of how the WDKHP arts residencies conveyed an important message to the children:

The truck and the kidney things, they can explain to the children, they might get [kidney disease] the same too, you know... They might get sick and be in the same boat."

He felt that the WDKHP should visit more often, and that program staff could advocate for increased health services, particularly dialysis units in remote communities.

\section{Conclusions}

This interview study faced considerable logistical challenges and this placed limits on the number and range of the interviews that could be conducted. Still, the messages that emerge from the interviews are starkly clear.

The WDKHP screened for kidney disease and health workers diagnosed this problem in the majority of the people in these communities. The people had reason to fear kidney disease, so it was very bad news. Contrary to what might have been expected, people responded positively to the program. The majority of the target population participated in clinical screening ${ }^{16}$ Community Leaders publically endorsed the project, many participants committed to changing their lifestyle and all participants endorsed the preventive message for others - especially the young. The data suggest that this outreach clinical service and communitybased approach to health promotion is wellaccepted, and worth implementing more broadly.

The WDKHP provides a clinical and preventive health service that brings necessary hightechnology medicine to these isolated areas in a way that is acceptable to the community, and positively received. What is critically important, however, is the careful integration of skilled Aboriginal health workers to encourage participation and clearly communicate health information. Community members valued this component of the project and in some cases this was contrasted with the poor communication in mainstream health services - a finding mirrored in previous research. ${ }^{25,26} \mathrm{It}$ seems likely that sustained integration of Aboriginal health workers and community in an ongoing program would benefit the understandings needed for better prevention and management of kidney disease.

While the clinical component of the WDKHP is of clear importance, this does not mean that the community is a passive recipient of the service. The problems associated with programs or health services that engender dependence, or undermine the social organisation of the community, have been well documented. ${ }^{27}$ The extensive consultation and planning that preceded the WDKHP - and its sensitive delivery - reinforced the messages of Elders and Community Leaders, who strongly promote the health benefits of traditional bush lifestyle, with lots of exercise and healthy 'bush tucker.28 This alignment in the delivery of health promotion messages likely contributed to the strong endorsement the WDKHP received from Elders and Community Leaders. The authority exercised by these Community Leaders represents a valuable preventive health resource. Better collaboration between governments and Community Leaders might harness this potent, localised resource, thus achieving better outcomes for people in remote communities. One practical outcome in the communities in this study would be supporting Community Leaders to ensure that shops established in the community sell healthy food and reasonably priced fresh fruit and vegetables. ${ }^{29}$

The value of the WDKHP outreach clinical service was illustrated most strongly by those who had relocated to a remote community, seeking refuge and a chance to escape unhealthy influences. ${ }^{30}$ These participants reported that the remote community setting enabled the adoption of a healthier lifestyle and a chance to escape unhealthy influences. Previous research has shown that enmeshed social networks and familial obligations can both facilitate and hinder the adoption of a healthy lifestyle. ${ }^{31}$ For some participants in this study, adopting a healthy lifestyle first required 'escape' and then 'refuge' in a community of other people also committed to healthier living. In this context, the provision of outreach clinical services can reduce exposure to unhealthy influences associated with regular visits to town. Importantly, this study shows how Aboriginal people based in towns or regional cities responded to illness or unhealthy situations by relocating to remote communities to adopt a healthier lifestyle. This study therefore cautions against the use of communitybased disease prevalence as an indicator of 'unhealthy' conditions at a local level.

There were high rates of participation in both the clinical screening and arts-health components of the project, ${ }^{16}$ and it is difficult to separate the unique contributions made by each. We note from participant responses that, in addition to promoting participation in clinical screening, the arts-health residencies made unique contributions to the health promotion messages of the WDKHP and produced a range of community arts outcomes that can be used to further promote these health promotion messages in the future. ${ }^{16,32}$ 


\section{Limitations}

While a number of measures were taken to build rapport with participants, some interviews were relatively short, with an absence of detail to contextualise responses. In some cases, there may have been discomfort associated with being interviewed by a non-Aboriginal researcher, or being interviewed in the presence of an Aboriginal co-researcher of the opposite gender. Where possible, the co-researcher was the same gender as the participant.

Most of the interviews were conducted with middle-aged or older adult community members. Due to the relatively small number of younger adults residing in these communities at the time, there were only a few interviews with young adults. As the interviews show, Community Leaders make a major commitment to maintain a place for younger people who might return from the city seeking refuge but, based on the current study, we could not tell how commonly this scenario occurs.

\section{Implications}

The communities in this study have social and economic value that is easily overlooked. While structural problems (such as difficulty accessing fresh fruit and vegetables) persist, the remote setting can enable and encourage physical activity, traditional 'bush tucker' diet, and connection to culture. Strong social organisation provides a framework for enforcing bans on alcohol and making these communities a place of refuge for those whose family or social situation makes it difficult to adopt healthy lifestyles. Remote communities have the potential to be healthpromoting settings, and this can be further augmented by sensitively structured and integrated programs, such as the WDKHP, visiting on a regular basis. In this way, the communities can provide a health and social service that is of considerable benefit to the health system. On the other hand, the social and financial cost associated with the breakdown of communities like Spinifex can be immense. The withdrawal of government services can effectively close down these communities.

The responses of community members in this study endorsed the design and implementation of the WDKHP. We conclude that an outreach clinical service, staffed and led by Aboriginal health workers, and integrated with arts-based approaches that reinforce messages from Elders, is an appropriate method of engaging communities in the prevention, early detection and management of diabetes and kidney disease.

\section{Acknowledgements}

The authors would like to acknowledge Samuel Stokes, Lorraine Scholson and Albert McKenzie for their contributions to this work as co-researchers. The authors thank the participants in the study and the three participating communities.

\section{References}

1. Australian Institute of Health and Welfare. Mortality and Life Expectancy of Indigenous Australians: 2008 to 2012. Canberra (AUST): AlHW; 2014

2. Larson A, Gillies M, Howard PJ, Coffin J. It's enough to make you sick: The impact of racism on the health of Aboriginal Australians. Aust N Z J Public Health. 2007;31(4):322-9.

3. Coggan M. Budget 2014: $\$ 534$ Million Cut to Indigenous Programs [Internet].Australian Broadcasting Commission. 2014 [cited 2015 Feb 1]. Available from: http://www.abc.net.au/news/2014-05-13/ budget-2014-534-cut-to-indigenous-programs-andhealth/5451144

4. Kagi J. Plan to Close More than 100 Remote Communities Would Have Severe Consequences, Says WA Premier [Internet]. Australian Broadcasting Commission. 2014 [cited 2015 Feb 1]. Available from: http://www.abc.net.au/news/2014-11-12/ indigenous-communities-closures-will-have-severeconsequences $/ 5886840$

5. Australian Institute of Health and Welfare. Aboriginal and Torres Strait Islander Health Performance Framework 2012 Report: Western Australia Supplementary Tables. Canberra (AUST): AlHW; 2013.

6. Cass A, Cunningham J, Wang ZQ, Hoy W. Regional variation in the incidence of end-stage renal disease in Indigenous Australians. Med J Aust. 2001;175(1):24-7.

7. Willis J.Fatal attraction: Do high-technology treatments for end-stage renal disease benefit Aboriginal patients in central Australia? Aust J Public Health. 1995;19(6):6039.

8. Williamson P. Let Me Die In My Country: Palliative Care Needs of Aboriginal People in the Kimberley and Pilbara Regions of Western Australia. Perth (AUST): Health Department of Western Australia; 1996.

9. O'Dea K, Rowley KG, Brown A. Diabetes in Indigenous Australians: Possible ways forward. Med J Aust. 2007;186(10):494-5.

10. Azzopardi P, Brown AD, Zimmet P, Fahy RE, Dent GA, Kelly $M$, et al. Type 2 diabetes in young Indigenous Australians in rural and remote areas: Diagnosis, screening, management and prevention. Med J Aust. 2012;197(1):32-6.

11. PyettP.Working together to reduce health inequalities: Reflections on a collaborative participatory approach to health research. Aust NZJ Public Health. 2002;26:332-6.

12. Jeffries-Stokes C, Stokes A, McDonald L, Stokes S, Daly J. A complex Aboriginal health project and the challenges for evaluation. AustNZJ Public Health. 2011;35(3):204-6.

13. Prior D.The meaning of cancer for Australian Aboriginal women; changing the focus of cancer nursing. Eur $J$ Oncol Nurs. 2009;13(4):280-6.

14. Anderson $K$, Cunningham J, Devitt J, Cass A. The IMPAKT study: Using qualitative research to explore the impact of end-stage kidney disease and its treatments on Aboriginal and Torres Strait Islander Australians. Kidney Int Suppl. 2013;3(2):223-6.

15. Dimer A. Alfie the tooth fairy (an animation). Med J Aust. 2011;194(10):539.
16. Jeffries-Stokes C, Stokes A,McDonald L. Pulkurlkpa-The joy of research in Aboriginal Communities. J Paediatr Child Health. 2015;51:1054-9.

17. Humphery K. Dirty questions: Indigenous health and 'Western research'. Aust N Z J Public Health. 2001;25(3):197-202.

18. Sherwood JM. Do No Harm: Decolonising Aboriginal Health Research [Unpublished Doctor of Philosophy Thesis]. Sydney (AUST): University of New South Wales; 2010.

19. Green J, Willis K, Hughes E, Small R, Welch N, Gibbs $L$, et al. Generating best evidence from qualitative research: The role of data analysis. Aust N Z J Public Health. 2007;31(6):545-50.

20. Bessarab D, Ng'andu B. Yarning about yarning as a legitimate method in Indigenous Research. Int J Crit Indigenous Stud. 2010;3(1):37-50.

21. Gifford P. Black and White and In Between: Arthur Dimer and the Nullarbor. Perth (AUST): Hesperian Press; 2002.

22. Morgan M.ADropin a Bucket:TheMountMargaretStory. Box Hill (AUST): United Aborigines Missions; 1986.

23. Arnold L. A Very Special Relationship: British Atomic Weapon Trials in Australia. London (UK): HMSO Publications Center; 1987.

24. Dousset L. Inclusion-Exclusion: Recasting the Issue of Boundaries for the Western Desert. Anthropol Forum. 2013;23(4):342-54.

25. Anderson K, Devitt J, Cunningham J, Preece C, Cass A. "All they said was my kidneys were dead": Indigenous Australian patients' understanding of their chronic kidney disease. Med J Aust. 2008;189(9):499-503.

26. Cass A, Lowell A, Christie M, Snelling PL, Flack M, Marrnganyin B, et al. Sharing the true stories: Improving communication between Aboriginal patients and healthcare workers. Med J Aust. 2002;176(10):466-70.

27. Trudgen R. Why Warriors Lie Down and Die. Darwin (AUST): Aboriginal Resource and Development Services; 2000. p. 270.

28. O'Dea K. Marked improvement in carbohydrate and lipid-metabolism in diabetic Australian Aborigines after temporary reversion to traditional lifestyle. Diabetes. 1984;33(6):596-603.

29. Scelza BA. Food scarcity, not economic constraint limits consumption in a rural Aboriginal community. Aust $J$ Rural Health. 2012;20(3):108-12.

30. Johnston FH, Jacups SP, Vickery AJ, Bowman D. Ecohealth and Aboriginal testimony of the nexus between human health and place. EcoHealth. 2007:4(4):489-99.

31. Johnston V, Thomas DP. Smoking behaviours in a remote Australian Indigenous community: The influence of family and other factors. Soc Sci Med. 2008;67(11):1708-16.

32. Sinclair C, Keelan P, Stokes S, Stokes A, Jeffries-Stokes C. Participatory video making for research and health promotion in remote Australian Aboriginal communities: Methodological and ethical implications. Int J Crit Indigenous Stud. 2015;8(1):2-16. 